\title{
Inertia Emulation in AC/DC Interconnected Power Systems Using Derivative Technique Considering Frequency Measurement Effects
}

\author{
E. Rakhshani, Member, IEEE and P. Rodriguez, Fellow, IEEE
}

\begin{abstract}
Virtual inertia is known as an inevitable part of the modern power systems with high penetration of renewable energy. Recent trend of research is oriented in different methods of emulating the inertia to increase the sustainability of the system. In the case of dynamic performance of power systems especially in automatic generation control (AGC) issue, there are concerns considering the matter of virtual inertia. This paper proposes an approach for analyzing the dynamic effects of virtual inertia in two-area AC/DC interconnected AGC power systems. Derivative control technique is used for higher level control application of inertia emulation. This method of inertia emulation is developed for two-area AGC system which is connected by parallel AC/DC transmission systems. Based on the proposed technique, the dynamic effect of inertia emulated by storage devices for frequency and active power control are evaluated. The effects of frequency measurement delay and PLL effect on are also considered by introducing a second-order function. Simulations performed by Matlab software demonstrate how virtual inertia emulation can effectively improve the performance of the power system. A detailed eigenvalue analysis is also performed to support the positive effects of proposed method.
\end{abstract}

Index Terms-Automatic Generation Control, Virtual Inertia, Interconnected Systems, Load Frequency Control.

\section{INTRODUCTION}

$\mathrm{L}$ IBERALIZATION of power industry as well as integration of large-scale Renewable Energy Sources (RES) are leading to make more adaption in the structure of conventional methodologies in power system. Automatic Generation Control (AGC) and Power Oscillation Damping (POD) analysis are very important in power system dynamic [1]-[3]. Deregulation of conventional scenarios of power industry considering high penetration of RES, make several adoptions in these important research areas [4]-[6]. The recent trends of research are through the adoption of previous

This work was partially supported by Spanish Science Ministry of Economy and Competitiveness under the projects ENE2013-48428-C2-2-R and ENE2014-60228-R. Any opinions, findings and conclusions or recommendations expressed in this material are those of the authors and do not necessarily reflect those of the host institutions or funders

Elyas Rakhshani, and Pedro Rodriguez, are with the Electrical Engineering Department of Technical University of Catalonia (UPC), SEER Research Center, Barcelona, Spain. Professor Rodriguez is also with the Department of Engineering, Loyola University Andalusia, 41014 Seville, Spain (e-mails: rakhshani@ieee.org, prodriguez@ee.upc.edu). concepts and conventional models considering new AC/DC complex scenarios with more application of DC interconnections and RES penetrations [7]-[9].

During the last decade, many researchers tried to propose new models for load frequency control, considering competitive environment, which was usually based on previous conventional generations. More details regarding generation by renewable resources considering Energy Storage Systems (ESS) were also proposed in many references [5]-[8]. Integration of RES is the main challenge for electric industry. During the steady state operation, the generation and consumption of energy must be balanced and any unbalancing will cause frequency and tie-line power mismatching. It is known that the rate of change of frequency (ROCOF) depends on the initial power mismatch and system inertia. Furthermore, power system is facing with high penetration of renewable resources with less inertia. The lack of inertia in modern power system, which caused by high penetration of RE sources and power electronic based components, will make a big challenge for the system. For example in PV generation there is not any mechanical part with inertia and also in case of wind and wave energy, because of decoupling the prime mover from electrical generator, they cannot contribute directly in total inertial of the system [9]. Therefore, technical methods for providing inertia will be very useful. In the generation level, applications of energy storage devices are very important in order to recover the lack of inertia in power electronic parts of generation [8] and facilitating RES to act as a conventional generator for frequency support issues [8]-[11].

At the transmission levels, in parallel with high penetration of renewable energy sources, there are huge increase of installation and applications of the High Voltage Direct Current (HVDC) interconnections especially after 2010. Positive effects of DC interconnections are clear and various advantages like frequency conversion, connections of asynchronous areas, more controllability, and expandability are reported by many researchers [12]-[14]. Power oscillation damping is another feature of HVDC links using POD controllers over the fast response electronic converters which can contribute in damping of inter-area oscillations [12]. Technologies that can help to increase power system flexibility are critical to reaching renewable energy integration targets. Energy storage Systems (ESS) are one of the promising tools for adding more beneficial advantages from 
HVDC and converter based systems [15]-[16]. Grid-scale energy storage is widely believed to have the potential to provide more flexibility [17] which led to research investigation on both the technical and economic issues surrounding ESS applications. A variety of battery technologies are being scaled up for grid application [17]. These have the flexibility to provide support services for customers and distribution grids as well as balancing or frequency regulation services. As reported in [18]-[19] battery and super-capacitor units can be used for high power applications. Application of Superconducting Magnetic Energy Storage (SMES) as bulk energy storage is also presented in [13] and [20]. An inertia emulation control (IEC) system is proposed in [15] which allow VSC-HVDC system to perform an inertial response in a similar fashion to synchronous machines.

In this paper, the inertia emulation concept using a derivative term control strategy suitable for frequency support applications in AGC interconnected systems is presented. The requirements in the frequency control and the net power interchange in a multi-area interconnected power system are settled by the automatic generation control. AGC concept is known as higher level control at the transmission level. This higher level control will generate the set-points for all the local components which are under control by their local controllers. Since, in real practice, the measurements of frequency is very important using derivative control method, the effects of frequency measurements and PLL dynamics are also added into the system modelling by considering a secondorder function.

In the following sections, the dynamic model of multi-area AGC system with AC/DC connection will be explained in section II. Then the concept of inertia emulation by derivative term with different model considering the models with and without PLL measurements is presented in section III. System analyses in a two-area system are given in section IV. Eigenvalue analyses are presented and discussed. Simulation results for a general case study are also presented in section $\mathrm{V}$ and finally the paper is concluded by section VI.

\section{SySTEM MODELING}

The power system is assumed to contain two areas and each area includes two generation companies (GENCO). The studied model consists of parallel AC and HVDC lines with added storage system. The block diagram studied load frequency control (LFC) system is shown in Fig. 1.

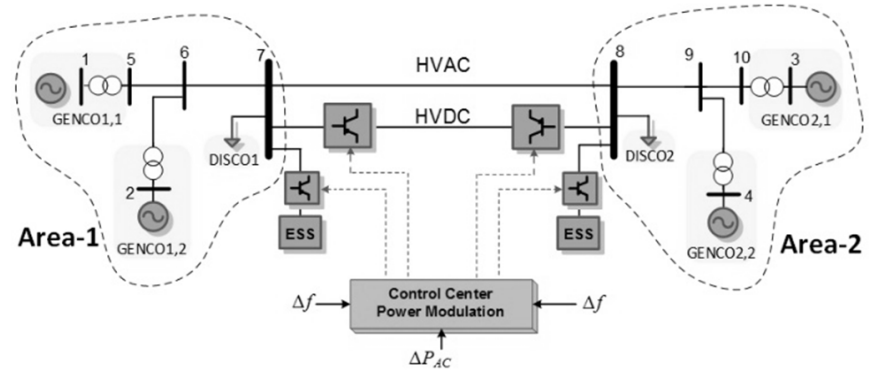

Fig. 1. The configuration of interconnected system with HVDC link.
In this model the power electronics are used as interface to control storage behaviour in response to AGC signals in order to improve frequency deviations [17]-[20].

The converter will be controlled to keep the storage element charged during normal operation and then help the system during contingencies. Based on this explanation, the ESS is used to provide additional inertia using derivative control method. A brief review regarding interconnected AGC modelling considering HVDC links is presented as follows.

\section{A. VSC-HVDC Transmission}

Modeling of voltage source converter especially for large scale power system is a very important issue. In case of HVDC analysis through complex AC grids, fast transient effects of switching part of VSC could be eliminated using average value models. Figure 2 shows the general structure of VSC-HVDC transmission system with their control actions. The main control blocks of VSC as shown in Fig. 2, are inner and outer control loops.

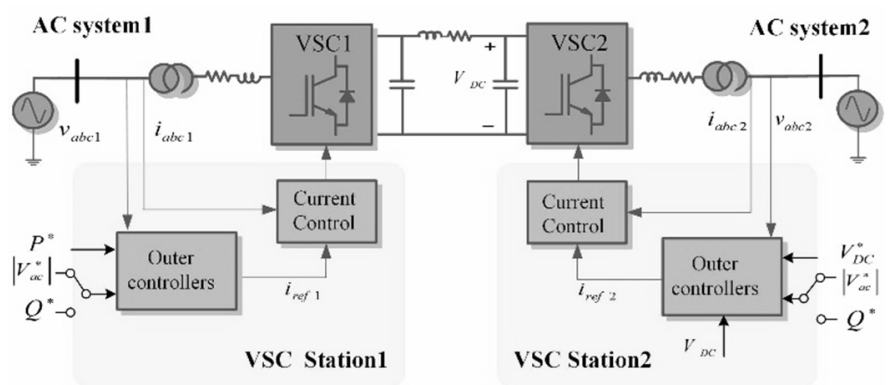

Fig. 2. General structure of VSC-HVDC control system.

Inner current control of HVDC is a fast dynamic control system for controlling the AC current in this system. The references were provided by outer control. For implementing inner control, different control methodology can be used [23]. By means of this current controller the voltage set-points for PWM converter will be provided. The outer control loops are responsible for generating the reference values mainly for AC current references. Reference for active current should be obtained from the DC voltage controller, active power and frequency controllers. Furthermore, the reference value for reactive current can be derived from $\mathrm{AC}$ voltage controller and reactive power controller. But depend on the special application, some of these controllers will be used.

Usually in HVDC system, one converter will be responsible of active power flow control and the other converter will control the level of DC link voltage.

\section{B. AGC structure for AC/DC system}

The load frequency control and AGC issue is well discussed in power system control literatures [1]-[4].To understand the concept of LFC problem, the Area Control Error (ACE) is introduced. In a two-area power system model, the ACE is defined as follows:

$$
A C E_{i}=\beta_{i} \Delta f_{i}+\Delta P_{i j}
$$

where the $\Delta P_{i j}$ is the net tie-line power flow variation between two areas $\left(\Delta P_{i j}=-\Delta P_{j i}\right), f$ is the system's frequency; $\beta_{i}$ is referred as the frequency bias and is generally 
referred to the tie-line bias control. Therefore, in a normal two-area AC link we have:

$$
\begin{gathered}
\Delta P_{i j}=\Delta P_{t i e, A C} \\
\Delta f=f_{\text {actual }}-f_{\text {schedule }}
\end{gathered}
$$

The state space presentation of $i^{\text {th }}$ area could be as follow:

$$
\Delta \omega_{i}=\frac{K_{p i}}{1+s T_{p i}}\left[\Delta P_{m, i k}-\Delta P_{L i}-\Delta P_{t i e, A C}\right]
$$

where $\Delta P_{L i}(i=1,2)$ is local load deviation, $K_{p i}$ is the power system gain, $T_{p i}$ is the power system time constant, $\Delta P_{m, i k}$ $(k=1,2)$ is the output of generation units and:

$$
K_{p i}=\frac{1}{D_{\text {sys }-i}}, T_{p i}=\frac{M_{\text {sys }-i}}{D_{\text {sys }-i}}=\frac{2 H_{\text {sys }-i} / \omega_{0}}{D_{\text {sys }-i}}
$$

Considering that $H_{s y s-i}$ and $D_{s y s-i}$ are inertia and damping. The rest of the variables could be defined as follows:

$$
\Delta P_{m, i k}=\frac{1}{1+s T_{t g, i k}}\left[\frac{\Delta \omega_{i}}{R_{i} \times 2 \pi}-K_{I i} \Delta P_{\text {refi }}\right]
$$

where $R_{k}(k=1: 4)$ is considered as droop for each generation company (GENCO). It is assumed each GENCO model consist of its turbine and governor model and $T_{t g}$ is overall the time constant of turbine-governor units in each GENCO [5] and [21]. The reference of generation units in $i^{\text {th }}$ area will be based on ACE and could be considered like this:

$$
\begin{gathered}
\Delta P_{\text {refi }}=\frac{A C E_{i}}{s}=\frac{1}{s}\left[\frac{\beta_{i}}{2 \pi} \Delta \omega_{i}+\Delta P_{t i e, A C}\right] \\
\Delta P_{t i e, A C}=\frac{T_{i j}}{s}\left[\Delta \omega_{i}-\Delta \omega_{j}\right]
\end{gathered}
$$

and $T_{i j}$ is also the synchronization power coefficient [1].

In order to model the HVDC link for dynamic analysis and implementing of the damping controller on the interconnected systems, the concept of Supplementary Power Modulation Controller (SPMC) is used [12]. The block diagram of the SPMC for modelling the VSC-HVDC in AGC power system is shown in Fig. 3. The power flow through the VSC-HVDC link is modulated based on the frequency variations at the two sides of the DC link and the variations of the AC power flow between the areas with the parallel VSC-HVDC stations. In this study, the dynamics of fast transient HVDC power electronic parts is neglected because the time constant of electronic parts is much smaller than mechanical part involved in dynamic analysis of power system.

The SPMC is designed as higher level damping controller to improve the performance of power system during load changes. The frequency deviations are used as a control signal for the VSC-HVDC units to control the power flow by changing the duty cycles of converters. The coordinated control strategy for this kind of HVDC link can be written as follows:

$$
\Delta x_{D C}=K_{f i} \Delta \omega_{i}+K_{A C} \Delta P_{t i e, A C}+K_{f i} \Delta \omega_{i}
$$

Considering that $\Delta x_{D C}$ is the control signal for the DC link (the desired DC power reference), $K_{f i}, K_{f j}$ and $K_{D C}$ are control gains. The HVDC link is also represented in the form of a transfer function:

$$
\Delta P_{D C}=G_{p} x_{D C}
$$

$$
G_{p}(s)=\frac{1}{1+s T_{d c}}
$$

where $T_{D C}$ is the time constant of the HVDC unit and $\Delta \mathrm{P}_{\mathrm{DC}}$ is DC power flow through the system.

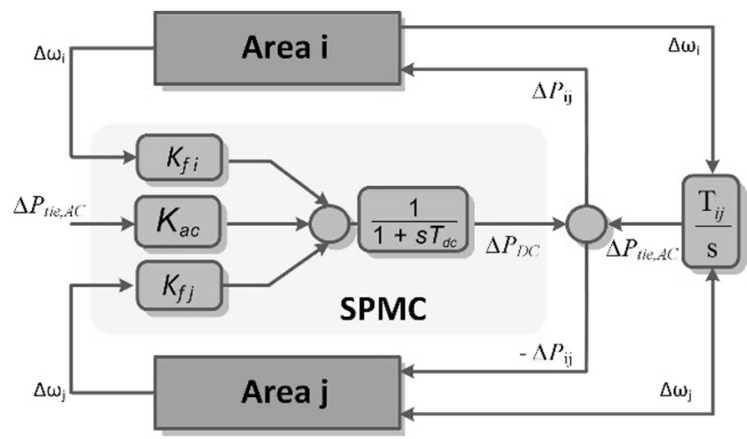

Fig. 3. Diagram of SPMC to the power system with parallel AC/DC links.

The $\Delta x_{\mathrm{DC}}$ is the input signal of HVDC which will be generated by frequency deviations of each interconnected areas and AC tie-line power deviations (in case of any parallel AC line with HVDC transmission link). As mentioned in [14] and [22] for this type of higher level control design, the proper time response could be between $100 \mathrm{~ms}$ to $500 \mathrm{~ms}$. In this study, the time constant is assumed $300 \mathrm{~ms}$ for $T_{D C}$. The total tie-line power variation in AC-DC system becomes:

$$
\Delta P_{i j}=\Delta P_{D C}+\Delta P_{t i e, A C}
$$

where $\Delta P_{D C}$ is a power modulation by HVDC link [1].

\section{VIRTUAL INERTIA BASED ON DERIVATIVE CONTROL}

\section{A. Virtual inertia concept}

If the active power through the power electronics converters of the storage device is controlled proportionally with the derivative of the grid frequency, a virtual inertia in the power system is emulated, which will contribute in enhancing the inertial response of the system against the change in the power demand. The control law for the active power of the power converter will be as follows [8]:

$$
P_{\text {emulate }}=k_{a} \omega_{0} \frac{d(\Delta \omega)}{d t}
$$

where $P_{\text {emulate }}$ is the emulated power, $k_{a}$ is the proportional conversion gain and $\omega_{0}$ is the nominal grid frequency [8]-[10].

\section{B. Proposed model of AGC with virtual inertia}

In this section, the proposed model for hybrid AC/DC link with the ability of storing energy and inertia emulation by derivative control is explained. This model is presented in Laplace domain with per unit value.

If the active power through the converter is controlled using the derivative of the frequency, a virtual inertia could be emulated in the system, thus enhancing the inertial response of conventional generator to changes in the power demand. The emulated power $\left(\Delta P_{E S S}\right)$ can be defined like this:

$$
\Delta P_{E S S, i}(s)=\frac{J_{i}}{1+s T_{E S S, i}}\left[s \Delta \omega_{i}(s)\right]
$$

where $T_{E S S, i}$ is also the time constant of added filter for 
imitating the dynamic control for electronic storage devices and $J_{i}$ is the controller gain representing the virtual inertia.

This control concept is the derivative control, which calculates the ROCOF and with a control gain modifies the active power reference of storage device for emulating the inertia. Adding the emulated power will modify (5)-(6) to the following equations:

$$
\begin{gathered}
\Delta \omega_{i}(s)=\frac{K_{p i}}{1+s T_{p i}}\left(\Delta P_{m, i k}-\Delta P_{t i e, A C}-\Delta P_{D C}\right. \\
\left.+\Delta P_{E S S, i}-\Delta P_{L i}\right)
\end{gathered}
$$

In order to perform detailed analysis for the two-area power system, the complete state space presentation of the studied system should be performed.

$$
\dot{\boldsymbol{x}}=\boldsymbol{A} \boldsymbol{x}+\boldsymbol{B u}
$$

where the state matrix $\mathrm{A}$ is partitioned as follows:

$$
A=\left[\begin{array}{ll}
A_{11} & A_{12} \\
A_{21} & A_{22} \\
A_{31} & A_{32}
\end{array}\right]_{(12 \times 12)}
$$

Therefore, each sub-matrix of two-area model is as follows:

$$
\begin{aligned}
& A_{11}=\left[\begin{array}{ccccccccc}
\frac{-1}{T_{P 1}} & 0 & \frac{K_{P 1}}{T_{P 1}} & \frac{K_{P 1}}{T_{P 1}} & 0 & 0 & 0 & 0 & \frac{-K_{P 1}}{T_{P 1}} \\
0 & \frac{-1}{T_{P 2}} & 0 & 0 & \frac{K_{P 2}}{T_{P 2}} & \frac{K_{P 2}}{T_{P 2}} & 0 & 0 & \frac{-K_{P 2}}{T_{P 2}} \\
\frac{-1}{2 \pi R_{1} T_{t g 1}} & 0 & \frac{-1}{T_{t g 1}} & 0 & 0 & 0 & \frac{-K_{I 1}}{T_{t g 1}} & 0 & 0 \\
\frac{-1}{2 \pi R_{2} T_{t g 2}} & 0 & 0 & \frac{-1}{T_{t g 2}} & 0 & 0 & \frac{-K_{I 1}}{T_{t g 2}} & 0 & 0 \\
0 & \frac{-1}{2 \pi R_{3} T_{t g 3}} & 0 & 0 & \frac{-1}{T_{t g 3}} & 0 & 0 & \frac{-K_{I 2}}{T_{t g 3}} & 0 \\
0 & \frac{-1}{2 \pi R_{4} T_{t g 4}} & 0 & 0 & 0 & \frac{-1}{T_{t g 4}} & 0 & \frac{-K_{I 2}}{T_{t g 4}} & 0
\end{array}\right]_{(6 \times 9)} \\
& A_{12}=\left[\begin{array}{ccc}
\frac{-K_{P 1}}{T_{P 1}} & \frac{-K_{P 1}}{T_{P 1}} & 0 \\
\frac{-K_{P 2}}{T_{P 2}} & 0 & \frac{-K_{P 2}}{T_{P 2}} \\
0 & 0 & 0 \\
\vdots & \vdots & \vdots \\
0 & 0 & 0
\end{array}\right]_{(6 \times 3)}, A_{21}=\left[\begin{array}{cccccc}
\frac{\beta_{1}}{2 \pi} & 0 & 0 & \ldots & 0 & 1 \\
0 & \frac{\beta_{2}}{2 \pi} & 0 & \ldots & 0 & -1 \\
\frac{T_{12}}{2 \pi} & \frac{-T_{12}}{2 \pi} & 0 & \ldots & 0 & 0
\end{array}\right]_{(3 \times 9)} \\
& A_{22}=\left[\begin{array}{ccc}
1 & 0 & 0 \\
-1 & 0 & 0 \\
0 & 0 & 0
\end{array}\right]_{(3 \times 3)}, A_{32}=\left[\begin{array}{ccc}
\frac{-1}{T_{D C}} & 0 & 0 \\
\alpha_{11.10} & \alpha_{11.11} & 0 \\
\alpha_{12.10} & 0 & \alpha_{12.12}
\end{array}\right]_{(3 \times 3)} \\
& A_{31}=\left[\begin{array}{ccccccccc}
\frac{K_{f 1}}{T_{d c}} & \frac{K_{f 2}}{T_{d c}} & 0 & 0 & 0 & 0 & 0 & 0 & \frac{K_{A C}}{T_{d c}} \\
\alpha_{11.1} & 0 & \alpha_{11.3} & \alpha_{11.4} & 0 & 0 & 0 & 0 & \alpha_{11.9} \\
0 & \alpha_{12.2} & 0 & 0 & \alpha_{12.5} & \alpha_{12.6} & 0 & 0 & \alpha_{12.9}
\end{array}\right]_{(3 \times 9)}
\end{aligned}
$$

As identified in state space presentation of global system, the parameters of derivative control are appeared in submatrices $A_{31}$ and $A_{33}$ which are related to derivative control state variables. In fact, these parameters are presented in $11^{\text {th }}$ and $12^{\text {th }}$ rows of the global system matrix A and could be used in analysing the system performance. Therefore, the elements of interest in matrix A are the elements which contain the control gains of derivative control components $\left(J_{1}\right.$ and $\left.J_{2}\right)$ in sub-matrices $A_{31}$ and $A_{33}$. These elements are as follows:

$$
a_{11,1}=\frac{-J_{1}}{T_{e s s 1} T_{p 1}}, a_{11,3}=\frac{J_{1} K_{p 1}}{T_{e s s 1} T_{p 1}}, a_{11,4}=\frac{J_{1} K_{p 1}}{T_{e s s 1} T_{p 1}},
$$

$$
\begin{gathered}
a_{11,9}=\frac{J_{1} K_{p 1}}{T_{e s s 1} T_{p 1}}, a_{11,10}=\frac{J_{1} K_{p 1}}{T_{e s s 1} T_{p 1}}, a_{11,11}=\frac{-J_{1} K_{p 1}}{T_{e s s 1} T_{p 1}}+\frac{-1}{T_{e s s 1}} \\
a_{12,2}=\frac{-J_{2}}{T_{e s s 2} T_{p 2}}, a_{12,5}=\frac{J_{2} K_{p 2}}{T_{e s s 2} T_{p 2}}, a_{12,6}=\frac{J_{2} K_{p 2}}{T_{e s s 2} T_{p 2}}, \\
a_{12,9}=\frac{J_{2} K_{p 2}}{T_{e s s 2} T_{p 2}}, a_{12,10}=\frac{J_{2} K_{p 2}}{T_{e s s 2} T_{p 2}}, a_{12,12}=\frac{-J_{2} K_{p 2}}{T_{e s s 2} T_{p 2}}+\frac{-1}{T_{e s s 2}}
\end{gathered}
$$

As shown in this model, we will have two more gains $\left(J_{1}\right.$ and $J_{2}$ ) related to inertia emulators for both areas. Usually, it would be possible to define a cost function for obtaining the optimum values for these control gains. These gains could be defined based on optimization theory by minimizing the following cost function [1]-[5]:

$$
J=\int\left[A C E_{1}^{2}+A C E_{2}^{2}\right] d t
$$

This cost function is the regular function which is based on the ISE (Integral of Squared Error) method [5]. It should be noted that the ACE is the area error which is consisted of frequency and tie-line deviations in each area. The control parameter for this case study could be obtained using the eq. (17) and classical FMINCON function in Matlab software. The generic non-linear optimization routine FMINCON solver could be used as a classical optimization which implements the Sequential Quadratic Programming (SQP) and the interiorpoint method for optimization of LFC problem [5].

\section{Dynamic effects of frequency measurements}

\section{1) Model of PLL Dynamics}

Usually the Phase Locked Loop (PLL) is one of the methods for synchronizing the converter to the grid and to measuring the frequency. Its dynamics can be approximated by a first-order or second-order model [23]. A general control structure of grid-connected converter with DC link and PLL is shown in Fig. 4. As shown in Fig. 4, reference values for active and reactive powers are coming for higher level control actions like droop frequency control. Related current references could be obtained based on the concept of Instantaneous Active-Reactive Control in the reference generation block [23].

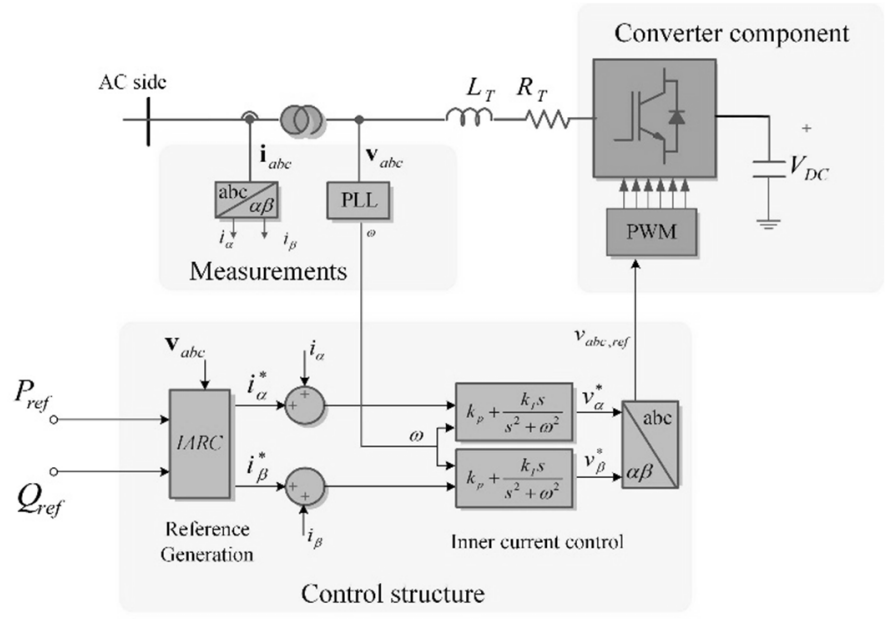

Fig. 4. A typical control structure of grid-connected converters.

The inner current loop controller is used for providing the reference voltage for converter. The angle of the grid voltage is provided by a PLL. This PLL can be used for estimating the 
frequency. This estimation is very important for proper action of inner current controller. The power references are coming from higher level control. The power reference is made by derivative control for emulating the inertia in two-area interconnected power system.

As explained before, the dynamics of converter and HVDC could be modelled as a first-order transfer function with a proper time constant imitating the control time of its components. In this study, in order to evaluate the dynamic effects of PLL and delayed measurements, more detailed model is considered by adding additional transfer function that model the dynamics of PLL and delayed measurements. The general block diagram of derivative control with PLL is presented in Fig. 5.

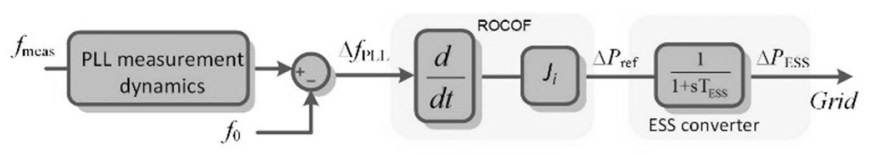

Fig. 5. Block diagram of derivative inertia emulation strategy.

For defining a proper model imitating the dynamics of PLL in higher level control analysis, a brief review is presented over the normal components of PLL. The basic structure of PLL is presented in Fig. 6. It contains of Phase Detector (FD), Loop filter (LF) and Voltage-Controlled Oscillator (VCO).

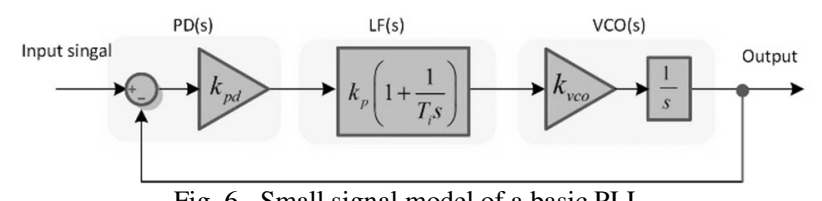

Fig. 6. Small signal model of a basic PLL.

Considering unitary values for PD and VCO gains of this closed-loop system $\left(k_{p d}=k_{v c o}=1\right)$, will give the following characteristic transfer functions. Open-loop transfer function:

$$
F_{O L}(s)=P D(s) \cdot \operatorname{LF}(s) \cdot \operatorname{VCO}(s)=\frac{k_{p} s+\frac{k_{p}}{T_{i}}}{s^{2}}
$$

Therefore, the close-loop transfer function is:

$$
H(s)=\frac{F_{O L}(s)}{1+F_{O L}(s)}=\frac{k_{p} s+\frac{k_{p}}{T_{i}}}{s^{2}+k_{p} s+\frac{k_{p}}{T_{i}}}
$$

This second-order transfer function can be written in a normalized way as follows:

$$
H_{P L L}(s)=\frac{2 \zeta \omega_{n} \boldsymbol{s}+\omega_{n}^{2}}{\boldsymbol{s}^{2}+2 \zeta \omega_{n} \boldsymbol{s}+\omega_{n}^{2}}
$$

where

$$
\omega_{n}=\sqrt{\frac{k_{p}}{T_{i}}} \text { and } \zeta=\frac{\sqrt{k_{p} T_{i}}}{2}
$$

The approximated time constant of this second-order function could be $\tau=\frac{1}{\zeta \omega_{n}}$ for $1 \%$ of steady state response [23].

\section{2) Modelling considering the PLL measurement dynamics}

For estimating or measuring the frequency different components like PLL can be used. These components will introduce some delay with specific dynamics to the system [22]. Therefore, it would be important to take into account these effects in term of derivative control implementation on frequency regulation of the transmission systems. As explained in previous section, the dynamic behaviours are like a second-order system which can be added in the LFC model. It should be mentioned that, the second-order block in the proposed LFC scheme is not the exact model of a PLL and is mainly representing the dynamics of a remote PLL with its delay for frequency measurement in high-level LFC applications. The modified model of two-area interconnected power system with derivative control method adding the PLL dynamics is depicted in Fig. 7. As explained before, in the second-order transfer function, there is one zero in the numerator. This zero will exhibit some overshoots in the system responses.

The relationship between input and output signals in this second-order system could be identified as follows:

$$
\ddot{y}+2 \zeta \omega_{n} \dot{y}+\omega_{n}^{2} y=2 \zeta \omega_{n} \dot{u}+\omega_{n}^{2} u
$$

The input signal $u(t)$ is the grid frequency $\Delta \omega_{i}$ which is related to other state of the global multi-area system and the output signal will consist of two states variables.

$$
\Delta Y_{P}=\Delta P_{E S S, P}=\left[\begin{array}{l}
\Delta x_{1, P} \\
\Delta x_{2, P}
\end{array}\right]
$$

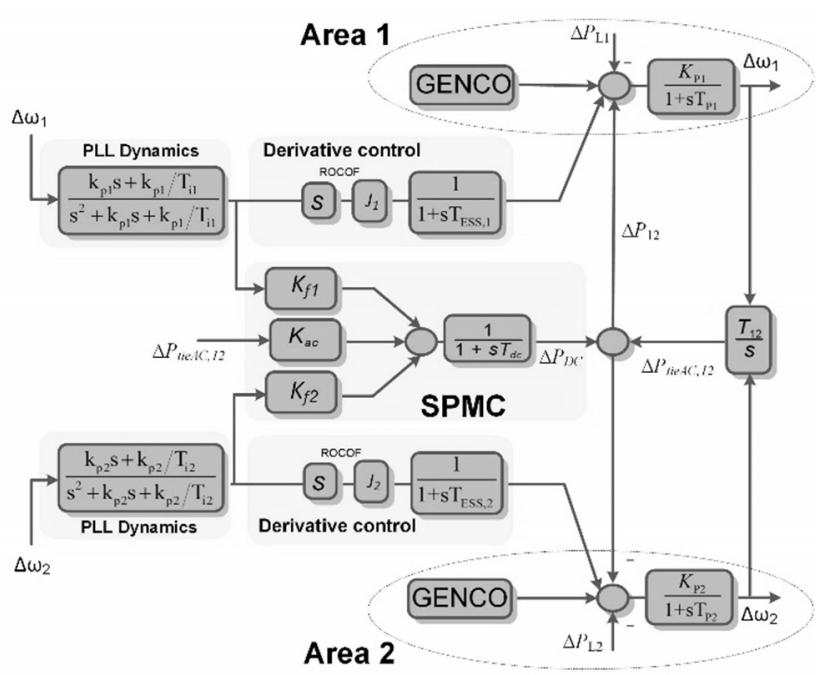

Fig.7. Proposed model for HVDC interconnected system with ESS derivative control and PLL dynamics.

Based on classic control concepts, this second-order system could be represented by a set of two linear state equations.

$$
\begin{aligned}
{\left[\begin{array}{c}
\Delta \dot{x}_{1, P} \\
\Delta \dot{x}_{2, P}
\end{array}\right]=\left[\begin{array}{cc}
0 & 1 \\
-\omega_{n}^{2} & -2 \zeta \omega_{n}
\end{array}\right]\left[\begin{array}{c}
\Delta x_{1, P} \\
\Delta x_{2, P}
\end{array}\right] } \\
+\left[\begin{array}{cc}
0 & 0 \\
2 \zeta \omega_{n} & \omega_{n}^{2}
\end{array}\right]\left[\begin{array}{l}
\Delta \dot{u} \\
\Delta u
\end{array}\right]
\end{aligned}
$$

Therefore, considering the input signals $\left(\Delta \omega_{i}\right)$ for $i^{\text {th }}$ area ( $\mathrm{i}=1: 2$ ) of two-area interconnected system, complete state equations of these new states could be as follows:

$$
\begin{gathered}
\Delta \dot{x}_{1, P i}=\Delta x_{2, P i} \\
\Delta \dot{x}_{2, P i}=\beta_{1, i} \Delta \omega_{i}+\beta_{2, i} \Delta P_{m j}+\beta_{3, i} \Delta P_{t i e, A C} \\
+\beta_{4, i} \Delta P_{D C}+\beta_{5, i} \Delta P_{E S S, i} \\
+\beta_{6, i} \Delta x_{1, P i}+\beta_{7, i} \Delta x_{2, P i} \\
+\beta_{8, i} \Delta P_{L i}
\end{gathered}
$$

where

$$
\beta_{1, i}=\frac{-2 \zeta_{i} \omega_{n i}}{T_{p i}}+\omega_{n i}^{2}, \beta_{2, i}=\frac{2 \zeta_{i} \omega_{n i} K_{p i}}{T_{p i}}
$$




$$
\begin{gathered}
\beta_{3, i}=\frac{-2 \zeta_{i} \omega_{n i} K_{p i}}{T_{p i}}, \beta_{4, i}=\frac{-2 \zeta_{i} \omega_{n i} K_{p i}}{T_{p i}} \\
\beta_{5, i}=\frac{-2 \zeta_{i} \omega_{n i} K_{p i}}{T_{p i}}, \beta_{6, i}=-\omega_{n i}^{2} \\
\beta_{7, i}=-2 \zeta_{i} \omega_{n i}, \beta_{8, i}=\frac{-2 \zeta_{i} \omega_{n i} K_{p i}}{T_{p i}}
\end{gathered}
$$

Based on presented information about adding a new second-order system, the linearized mathematical presentation of the studied two-area system could be update as follows:

$$
\Delta \dot{\mathbf{x}}=A_{p} \Delta \mathbf{x}+B_{p} \Delta \mathbf{u}
$$

where $A_{p}$ is the new state matrix considering the dynamics of PLL and measurements in the system with derivative control.

$$
\boldsymbol{A}_{\boldsymbol{p}}=\left[\begin{array}{ll}
\boldsymbol{A}_{p, 11} & \boldsymbol{A}_{p, 12} \\
\boldsymbol{A}_{p, 21} & \boldsymbol{A}_{p, 22}
\end{array}\right]_{(16 \times 16)}
$$

Therefore, $A_{p, 11}$ could be extracted from sub-matrices $A_{11}$ and $A_{12}$ of (17) and the new sub-matrices are:

$$
\begin{aligned}
& A_{p, 11}=\left[\begin{array}{l}
A_{11} \\
A_{21}
\end{array}\right]_{(9 \times 9)}, A_{p, 12}=\left[\begin{array}{cccccc}
\frac{-K_{p 1}}{T_{p 1}} \frac{-K_{p 1}}{T_{p 1}} & 0 & 0 & \ldots & 0 \\
\frac{K_{p 2}}{T_{p 2}} & 0 & \frac{-K_{p 2}}{T_{p 2}} & 0 & \ldots & 0 \\
0 & 0 & 0 & 0 & \ldots & 0 \\
\vdots & \vdots & \vdots & \vdots & \vdots \\
1 & 0 & 0 & 0 & \ldots & 0 \\
-1 & 0 & 0 & 0 & \ldots & 0 \\
0 & 0 & 0 & 0 & \ldots . & 0
\end{array}\right]_{(9 \times 7)} \\
& A_{p, 21}=\left[\begin{array}{cccccccc}
0 & 0 & 0 & 0 & 0 & 0 & 00 & \frac{K_{a c}}{T_{d c}} \\
\frac{J_{1} \beta_{1,1}}{T_{e s s, 1}} & 0 & \frac{J_{1} \beta_{2,1}}{T_{e s s, 1}} & \frac{J_{1} \beta_{2,1}}{T_{e s s, 1}} & 0 & 0 & 0 & \frac{-J_{1} \beta_{3,1}}{T_{e s s, 1}} \\
0 & \frac{J_{2} \beta_{1,2}}{T_{e s s, 2}} & 0 & 0 & \frac{J_{2} \beta_{2,2}}{T_{e s s, 2}} & \frac{J_{2} \beta_{2,2}}{T_{e s s, 2}} & 0 & \frac{J_{2} \beta_{3,2}}{T_{e s s, 2}} \\
0 & 0 & 0 & 0 & 0 & 0 & 00 & 0 \\
\beta_{1,1} & 0 & \beta_{2,1} & \beta_{2,1} & 0 & 0 & 00 & \beta_{3,1} \\
0 & 0 & 0 & 0 & 0 & 0 & 00 & 0 \\
0 & \beta_{1,2} & 0 & 0 & \beta_{2,2} & \beta_{2,2} & 00 & \beta_{3,2}
\end{array}\right]_{(7 \times 9)} \\
& A_{p, 22}=\left[\begin{array}{ccccccc}
\frac{-1}{T_{d c}} & 0 & 0 & \frac{K_{f 1}}{T_{d c}} & \frac{K_{f 1}}{T_{d c}} & \frac{K_{f 2}}{T_{d c}} & \frac{K_{f 2}}{T_{d c}} \\
\frac{-J_{1} \beta_{4,1}}{T_{e s s}} \frac{J_{1} \beta_{5,1}-1}{T_{e s s .1}} & 0 & \frac{J_{1} \beta_{6,1}}{T_{e s s, 1}} & \frac{J_{1}\left(\beta_{7,1}+1\right)}{T_{e s s .1}} & 0 & 0 \\
\frac{J_{2} \beta_{4,2}}{T_{e s s .2}} & 0 & \frac{J_{2} \beta_{5,2}-1}{T_{e s s .2}} & 0 & 0 & \frac{J_{2} \beta_{6,2}}{T_{e s s, 2}} & \frac{J_{2}\left(\beta_{7,2}+1\right)}{T_{e s s .2}} \\
0 & 0 & 0 & 0 & 1 & 0 & 0 \\
\beta_{4,1} & \beta_{5,1} & 0 & \beta_{6,1} & \beta_{7,1} & 0 & 0 \\
0 & 0 & 0 & 0 & 0 & 0 & 1 \\
-\beta_{4,2} & 0 & \beta_{5,2} & 0 & 0 & \beta_{6,2} & \beta_{7,2}
\end{array}\right]_{(7 \times 7)}
\end{aligned}
$$

\section{SySTEM ANALYSIS}

In this section, the analysis are focused on two parts. The first part is focused on the effects of derivative control gains and inertia itself on the system performance and the second part of analysis is focused on the effects of the frequency measurements dynamics on the system with virtual inertia.

\section{A. Eigenvalue analysis of virtual inertia}

The dynamic effects of inertia emulation by derivative control method for presented system in eq. (16) are analysed. Analyses are performed in Matlab platform and the system parameters are given by [1] and [12]. The main objective of this section is to analyse the effects of derivative control gains on the performance of the system. Based on presented state space models in section IV.B, the eigen-value of two-area power system for different parameters of derivative control gains, as shown in Table I and II, could be obtained.
In Table I, the values of all the modes for the system with derivative control are compared for different values of control gain $J_{1}$ (located in area one). From the presented information in this table it can be observed that the first mode $\lambda_{1}$ has the highest variation. It means that this mode will be more sensitive to the change of parameter in area one.

In order to assess the system behaviours over a wide range of parameter variation, eigen trajectory is also performed. In Fig. 8-a, the movements of all modes after changing the derivative control gain $\left(J_{1}\right)$ for a very wide range is presented.

TABLE I

EIGENVALUES FOR DIFFERENT VALUES OF $\mathrm{J}_{1}$ (WITH $\mathrm{J}_{2}=0.093$ ).

\begin{tabular}{|c|c|c|c|c|}
\hline Modes & $J_{I}=0.1$ & $\boldsymbol{J}_{\boldsymbol{l}}=\mathbf{0 . 8}$ & $J_{I}=2.2$ & $J_{I}=2.9$ \\
\hline $\boldsymbol{\lambda}_{\mathbf{1}}$ & -58.45 & -195.6 & -470.12 & -607.41 \\
\hline $\boldsymbol{\lambda}_{\mathbf{2}}$ & -52.96 & -52.97 & -52.96 & -52.96 \\
\hline $\boldsymbol{\lambda}_{\mathbf{3}}$ & -23.25 & -23.65 & -22.51 & -22.51 \\
\hline $\boldsymbol{\lambda}_{\mathbf{4}}$ & $-0.78+\mathrm{i} 1.87$ & $-1.17+\mathrm{i} 1.90$ & $-1.25+\mathrm{i} 1.89$ & $-1.27+\mathrm{i} 1.89$ \\
\hline $\boldsymbol{\lambda}_{\mathbf{5}}$ & $-0.78-\mathrm{i} 1.87$ & $1.17-\mathrm{i} 1.90$ & $-1.25-\mathrm{i} 1.89$ & $-1.27-\mathrm{i} 1.89$ \\
\hline $\boldsymbol{\lambda}_{\mathbf{6}}$ & $-0.21+\mathrm{i} 0.36$ & $\mathbf{- 0 . 1 8 0}$ & -0.0007 & -0.0005 \\
\hline $\boldsymbol{\lambda}_{\mathbf{7}}$ & $-0.21-\mathrm{i} 0.36$ & $-0.19+\mathrm{i} 0.24$ & $-0.22+\mathrm{i} 0.22$ & $-0.23+\mathrm{i} 0.22$ \\
\hline $\boldsymbol{\lambda}_{\mathbf{8}}$ & -0.427 & $-0.19-\mathrm{i} 0.24$ & $-0.22-\mathrm{i} 0.22$ & $-0.23-\mathrm{i} 0.22$ \\
\hline $\boldsymbol{\lambda}_{\mathbf{9}}$ & -2.154 & -2.201 & -2.201 & -2.201 \\
\hline $\boldsymbol{\lambda}_{\mathbf{1 0}}$ & -2.248 & -2.491 & -2.571 & -2.590 \\
\hline$\lambda_{\mathbf{1 1}}$ & -2.695 & -2.701 & -2.701 & -2.701 \\
\hline $\boldsymbol{\lambda}_{\mathbf{1 2}}$ & -2.631 & -2.631 & -2.631 & -2.631 \\
\hline
\end{tabular}

After increasing the control gain $\left(J_{1}\right)$, the $6^{\text {th }}$ mode $\left(\lambda_{6}\right)$ is another mode which has some negative effects on the system by moving to the right. Therefore, it is obvious that designing the control gain will be a trade-off for having the most optimum response. Participation factors for different modes are presented in Table III. As shown in this table the main participation for $\lambda_{1,2}$ are from the power states of ESS elements. While the main participants for mode $\lambda_{6}$ are the area control error and frequency deviations $\left(\triangle A C E_{1}, \Delta \omega_{1}, \Delta \omega_{2}\right)$.

The effect of various changes on the other parameter $\left(J_{2}\right)$ which is located in Area2 (area without contingency) is also presented in Table II. As shown in Table II, the second mode $\lambda_{2}$ will have the most variation for different values of $J_{2}$ which will indicate that the second mode of the system is more sensitive to the changes of $J_{2}$. It is obvious that by increasing the $J_{2}$ values, several modes (like: $\lambda_{4}, \lambda_{5}, \lambda_{6}, \lambda_{7}$ and $\lambda_{8}$ ) will move to the right which will deteriorate the dynamic performance of the system.

TABLE II

EIGENVALUES FOR DIFFERENT VALUES OF $\mathrm{J}_{2}$ (WITH $\mathrm{J}_{1}=0.85$ ).

\begin{tabular}{|c|c|c|c|c|}
\hline Modes & $J_{2}=0.01$ & $J_{2}=0.05$ & $J_{2}=0.15$ & $J_{2}=0.5$ \\
\hline$\lambda_{\mathbf{1}}$ & -209.32 & -209.32 & -209.32 & -209.32 \\
\hline$\lambda_{\mathbf{2}}$ & -40.10 & -46.23 & -61.90 & -116.87 \\
\hline$\lambda_{\mathbf{3}}$ & -22.42 & -22.55 & -22.70 & -22.83 \\
\hline$\lambda_{\mathbf{4}}$ & $-1.29+\mathrm{i} 1.7$ & $-1.22+\mathrm{i} 1.82$ & $-1.15+\mathrm{i} 1.97$ & $-1.10+\mathrm{i} 2.01$ \\
\hline $\boldsymbol{\lambda}_{\mathbf{5}}$ & $-1.29-\mathrm{i} 1.7$ & $-1.22-\mathrm{i} 1.82$ & $-1.15-\mathrm{i} 1.97$ & $-1.10-\mathrm{i} 2.01$ \\
\hline$\lambda_{\mathbf{6}}$ & $-0.22+\mathrm{i} 0.11$ & -0.201 & -0.15 & $-0.08+\mathrm{i} 0.22$ \\
\hline$\lambda_{\mathbf{7}}$ & $-0.22-\mathrm{i} 0.11$ & $-0.24+\mathrm{i} 0.20$ & $-0.16+\mathrm{i} 0.24$ & $-0.08-\mathrm{i} 0.22$ \\
\hline$\lambda_{\mathbf{8}}$ & -0.460 & $-0.24-\mathrm{i} 0.20$ & $-0.16-\mathrm{i} 0.24$ & -0.101 \\
\hline$\lambda_{\mathbf{9}}$ & -1.80 & -2.07 & -2.30 & -2.65 \\
\hline$\lambda_{\mathbf{1 0}}$ & -2.50 & -2.50 & -2.50 & -2.50 \\
\hline$\lambda_{\mathbf{1 1}}$ & -2.69 & -2.69 & -2.70 & -2.55 \\
\hline$\lambda_{\mathbf{1 2}}$ & -2.63 & -2.63 & -2.63 & -2.63 \\
\hline
\end{tabular}



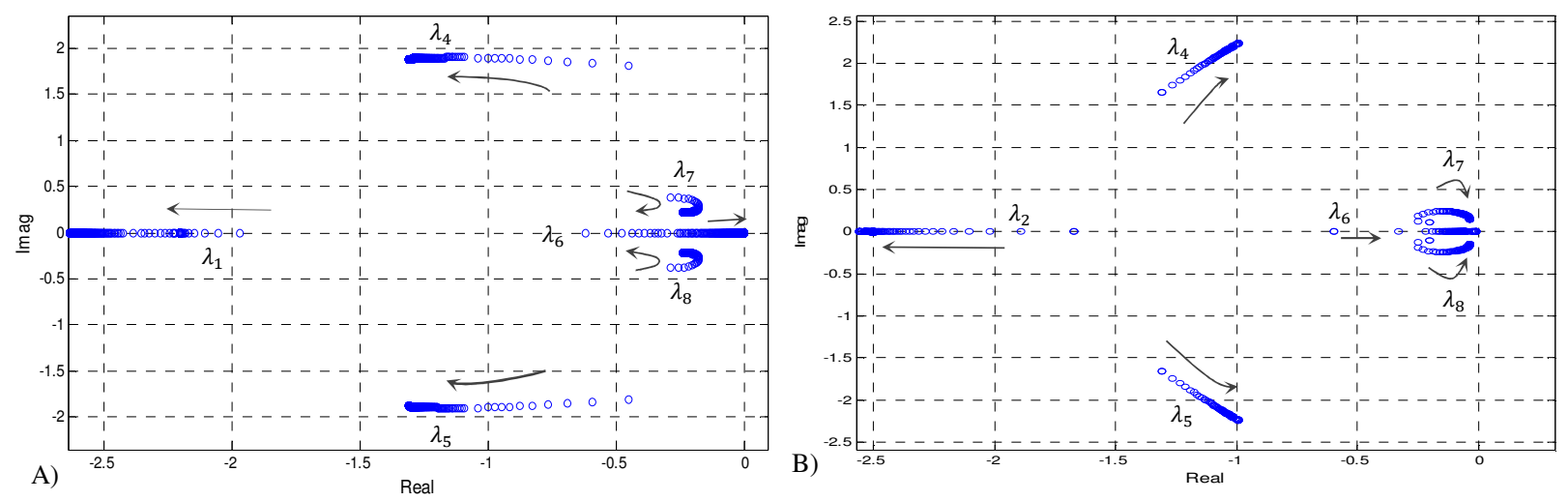

Fig. 8. Eigenvalue trajectory of dominant poles over changes of controller gains, (arrow direction indicates increase in $J_{\mathrm{i}}$ ). A) $J_{1}$ variations, B) $J_{2}$ variations.

Likewise, in Fig. 8.b, the movements of modes for different value of $J_{2}$ are presented. It can be observed that, by increasing $J_{2}$, several modes are approaching to a less stable and more oscillatory region. Therefore, it is better to keep smaller values for $J_{2}$ and give the main responsibility to the derivative control which is located in the same area of contingency $\left(J_{1}\right.$ in the first area).

\section{TABLE III}

PARTICIPATION OF SYSTEM STATES FOR DIFFERENT MODES

\begin{tabular}{|c|c|c|}
\hline Modes & Associated states & Participation factors \\
\hline$\lambda_{1}$ & $\Delta \boldsymbol{P}_{E S S 1}$ & 0.9982 \\
\hline$\lambda_{2}$ & $\Delta \boldsymbol{P}_{E S S 2}$ & 1.0054 \\
\hline$\lambda_{3}$ & $\Delta P_{t i e, D C}, \Delta \omega_{1}, \Delta \omega_{2}$ & $1.1053,0.1517,0.036$ \\
\hline$\lambda_{4}$ & $\Delta P_{t i e, A C}, \Delta \omega_{1}, \Delta \omega_{2}$ & $0.3661,0.8140,0.402$ \\
\hline$\lambda_{5}$ & $\Delta P_{t i e, A C}, \Delta \omega_{1}, \Delta \omega_{2}$ & $0.3661,0.8140,0.402$ \\
\hline$\lambda_{6}$ & $\triangle A C E_{1}, \Delta \omega_{1}, \Delta \omega_{2}$ & $1.2578,0.3975,0.220$ \\
\hline$\lambda_{7}$ & $\Delta A C E_{2}, \Delta \omega_{1}, \Delta \omega_{2}$ & $0.5801,0.4537,0.544$ \\
\hline$\lambda_{8}$ & $\Delta A C E_{2}, \Delta \omega_{1}, \Delta \omega_{2}$ & $0.5801,0.4537,0.544$ \\
\hline$\lambda_{9}$ & $\Delta P_{m 3}, \Delta P_{m 4}$ & $0.8498,0.3692$ \\
\hline$\lambda_{10}$ & $\Delta P_{m 1}, \Delta P_{m 2}$ & $0.5184,0.4850$ \\
\hline$\lambda_{11}$ & $\Delta P_{m 3}, \Delta P_{m 4}$ & $0.7504,0.2589$ \\
\hline$\lambda_{12}$ & $\Delta P_{m 1}, \Delta P_{m 2}$ & $0.4830,0.5170$ \\
\hline
\end{tabular}

A general comparison of eigen-values for different systems is presented in Table IV. It is obvious that adding derivative control for emulating the inertia to the system will improve the dynamic performance by shifting the eigenvalues to a better place in the left half of the s-plane.

TABLE IV

CONTROL PARAMETERS FOR STUDIED MODEL

\begin{tabular}{|c|c|c|c|}
\hline Modes & AC system & AC/DC System & $\begin{array}{c}\text { AC/DC with } \\
\text { Derivative Control }\end{array}$ \\
\hline $\boldsymbol{\lambda}_{\mathbf{1}}$ & $-0.027+0.825 \mathrm{i}$ & -23.9299 & -209.32 \\
\hline $\boldsymbol{\lambda}_{\mathbf{2}}$ & $-0.027-0.825 \mathrm{i}$ & $-0.494+1.6611 \mathrm{i}$ & -52.96 \\
\hline $\boldsymbol{\lambda}_{\mathbf{3}}$ & $-0.342+0.399 \mathrm{i}$ & $-0.494-1.6611 \mathrm{i}$ & -22.63 \\
\hline $\boldsymbol{\lambda}_{\mathbf{4}}$ & $-0.342-0.399 \mathrm{i}$ & $-0.343+0.4245 \mathrm{i}$ & $-1.1+1.9 \mathrm{i}$ \\
\hline $\boldsymbol{\lambda}_{\mathbf{5}}$ & -0.7023 & $-0.343-0.4245 \mathrm{i}$ & $-1.1-1.9 \mathrm{i}$ \\
\hline $\boldsymbol{\lambda}_{\mathbf{6}}$ & -1.8271 & -0.8974 & -0.201 \\
\hline $\boldsymbol{\lambda}_{\mathbf{7}}$ & -2.1073 & $-1.937+0.1752 \mathrm{i}$ & $-0.1+0.2 \mathrm{i}$ \\
\hline $\boldsymbol{\lambda}_{\mathbf{8}}$ & -2.6872 & $-1.937-0.1752 \mathrm{i}$ & $-0.1-0.2 \mathrm{i}$ \\
\hline $\boldsymbol{\lambda}_{\mathbf{9}}$ & -2.6316 & -2.6850 & -2.30 \\
\hline $\boldsymbol{\lambda}_{\mathbf{1 0}}$ & ------- & -2.6316 & -2.50 \\
\hline $\boldsymbol{\lambda}_{\mathbf{1 1}}$ & ------- & ------- & -2.70 \\
\hline $\boldsymbol{\lambda}_{\mathbf{1 2}}$ & ------- & ------ & -2.63 \\
\hline
\end{tabular}

\section{B. Required energy for inertia emulation}

Usually, it would be difficult to identify the exact amount of required energy to be stored. This is due to dynamic nature of rotational machines and unpredictability of load variations in terms of its location and their degree of severity [24]. According Eq. (4), after each sudden load changing, the machine will accelerate or decelerate. It is desirable to have a very fast control strategy to follow the derivations of the signals. This ability can be accomplished using fast power electronic components, while the problem of lack of energy reserve for emulating the inertia can be solved by using the storage devise. Any mismatch between electrical power and mechanical power will bring the accelerating power named here $P_{a}$. During each transient, the value of accelerating power should be minimized quickly. However, the stability margin of the studied system can be increased if a certain amount of power is added/subtracted from this value of accelerating power. For doing that, the equation of motion introducing the contribution of virtual inertia power can be presented as follows:

$$
\frac{2 H}{\omega_{s}} \Delta \dot{\omega}=\Delta P_{a} \pm \Delta P_{s}
$$

where $P_{s}$ can be the emulated power supplied/absorbed by the storage system. Since the time response of storage device is in the range of milliseconds until seconds, a constant value for input mechanical power can be assumed. Therefore, by neglecting the damping factor, a linearized equation for estimating the required energy can be obtained.

In multi-area interconnected AGC systems, in the case of any help from a neighbour area (especially for fast DC links) the contributions of tie-line AC/DC power could be also considered. Based on these assumptions, the total amount of storage power is equal to the total power mismatch related to load variations subtracted by the tie-line contributions in multi-area interconnected systems:

$$
\Delta P_{s}=\Delta P_{d}-\left(\Delta P_{D C}+\Delta P_{a c}\right)
$$

where $\Delta P_{d}$ is load variations, $\Delta P_{D C}$ is the deviations of $\mathrm{dc}$ power flow and $\Delta P_{a c}$ is the deviations of $\mathrm{AC}$ tie-line power flow. Usually in order to assure enough capacity, the size of storage should be based on the worst case scenario. The usual faulty situation from the dynamic point of view, in the case of LFC analysis, could be a usual disturbance for generation drops or load variation. For normal contingencies like normal load variations, the mismatch value can be determined based on the average statistical exchange between load and generation. Short term and long term demand forecasting 
based on the history of the statistical exchange power is one of the tools for predicting the possible load variation. It is also possible to derive some parameters realizing the amount of ESS power based on the virtual inertia control.

Considering Fig. 9, the following parameters can be defined:

- $\left.P_{\text {char }}\right|_{t_{\text {max }}}$ : maximum charging power.

- $\left.P_{\text {disch }}\right|_{t_{\text {max }}}$ : maximum discharging power.

- $E_{\text {char }}$ : maximum charging capacity (equal to area B).

- $E_{\text {char }}$ : maximum discharging capacity (equal to area A).

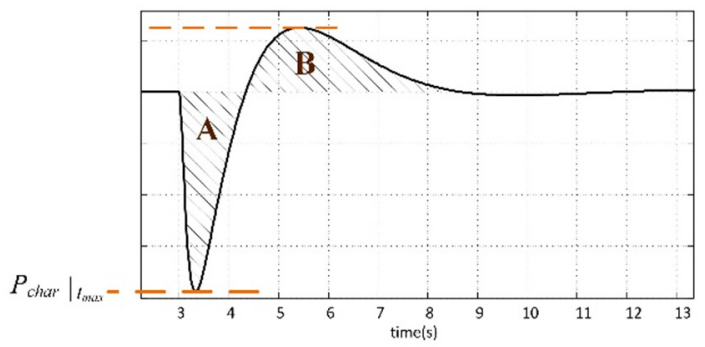

Fig. 9. A general example of injected power by storage device.

In practice, the energy of ESS component can be calculated according to the following equation:

$$
E_{e s s}=\int_{0}^{t} P_{e s s}(t) d t+E_{e s s, 0}
$$

where $P_{e s s}$ is the instantaneous power of storage device and $E_{\text {ess }, 0}$ is the initial stored energy. Amount of energy for different control gains are obtained and presented in Figs. 10 and 11. The required energy for $\mathrm{ESS}_{1}$ (for $J_{1}=0.8$ ) is around 0.6 p.u. Thus, knowing the base values for each application, the real values of energy with the required DC capacitance can be calculated.

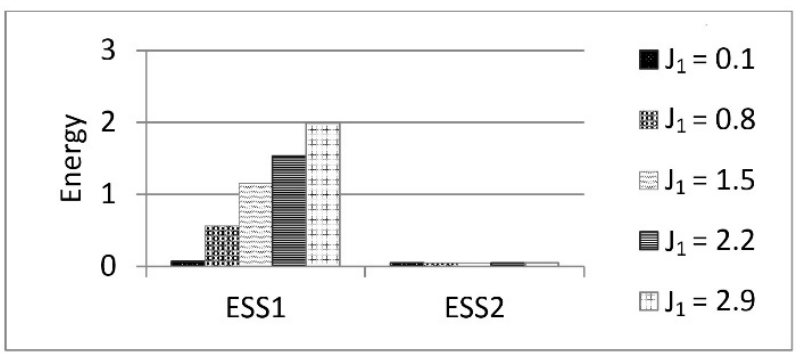

Fig. 10. Per unit values of energy for different $J_{1}$ (when $J_{2}=0.09$ ).

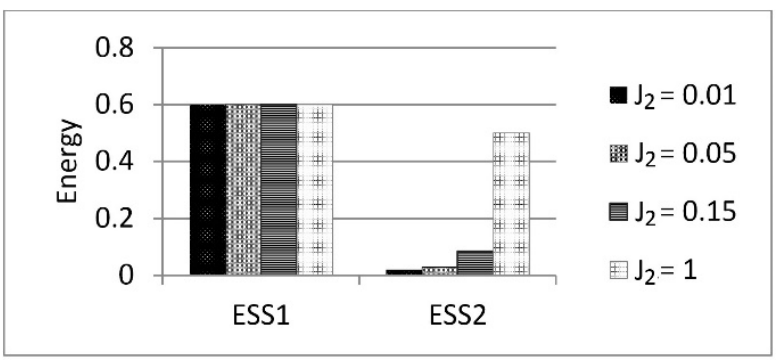

Fig. 11. Per unit values of energy for different $\mathrm{J}_{2}$ (when $\mathrm{J}_{1}=0.8$ ).

In case of having HVDC links, since the variations in DC link voltage of HVDC system is limited, the stored energy in DC link may not be enough for effective action. Therefore, considering these analysis, the required energy from additional storage system can be identified.

\section{Analysis of frequency measurements and PLL effects}

In this section, the dynamic effects of measurement mainly related to second-order PLL effects of ESS based converter system is analysed. A general comparison between the system of inertia emulation with and without PLL is presented in Fig 12. To have a fair comparison for higher level application, a range between $100 \mathrm{~ms}$ to $700 \mathrm{~ms}$ delay could be assumed for the time response of second-order function. It is assumed that this time constant is associated to a remote PLL dynamics, communications and measurements together [23].

The system input is one step changes around $0.03 \mathrm{pu}$. at $t=3 \mathrm{~s}$ in Area1. The control parameters for the studied power model are given Table V. The dynamic behaviours for several systems are presented and compared.

TABLE V

CONTROL PARAMETERS FOR STUDIED MODEL

\begin{tabular}{|c|c|}
\hline Parameters & Value \\
\hline$K_{f 1}$ & 0.3 \\
\hline$K_{f 2}$ & 0.1 \\
\hline$K_{A C}$ & 2.2 \\
\hline$J_{1}$ & 0.85 \\
\hline$J_{2}$ & 0.093 \\
\hline
\end{tabular}

The comparisons are mainly related to the normal case with AC line, AC/DC lines and AC/DC with inertia emulation capability.
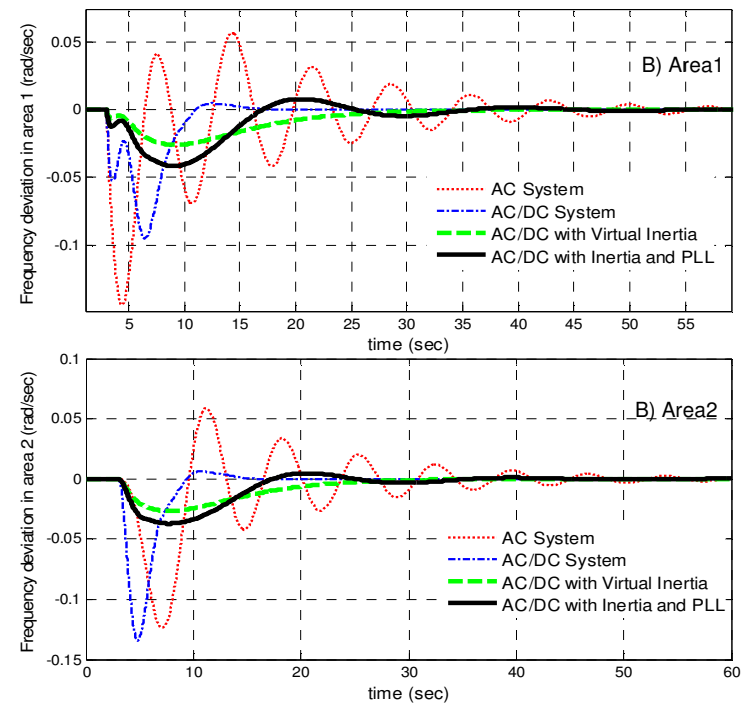

Fig. 12. Frequency deviation of the systems adding PLL effects ( $\mathrm{rad} / \mathrm{sec})$.

As shown in Fig. 12, the frequency deviation of the system in area one is compared with the normal $\mathrm{AC}$ system (the red curve), the system with normal AC/DC line (blue), the system with PLL (green) and the system without PLL (black). From these responses, it could be concluded that adding a PLL is affecting the dynamic performance of the system. Note that, because of the zero in the numerator of second-order model, the system exhibits more overshoots in dynamic responses. The superiority of the inertial control method compared to the other systems is due to the fast response of converter based energy storage devices which can provide a fast inertia response during load variations. 

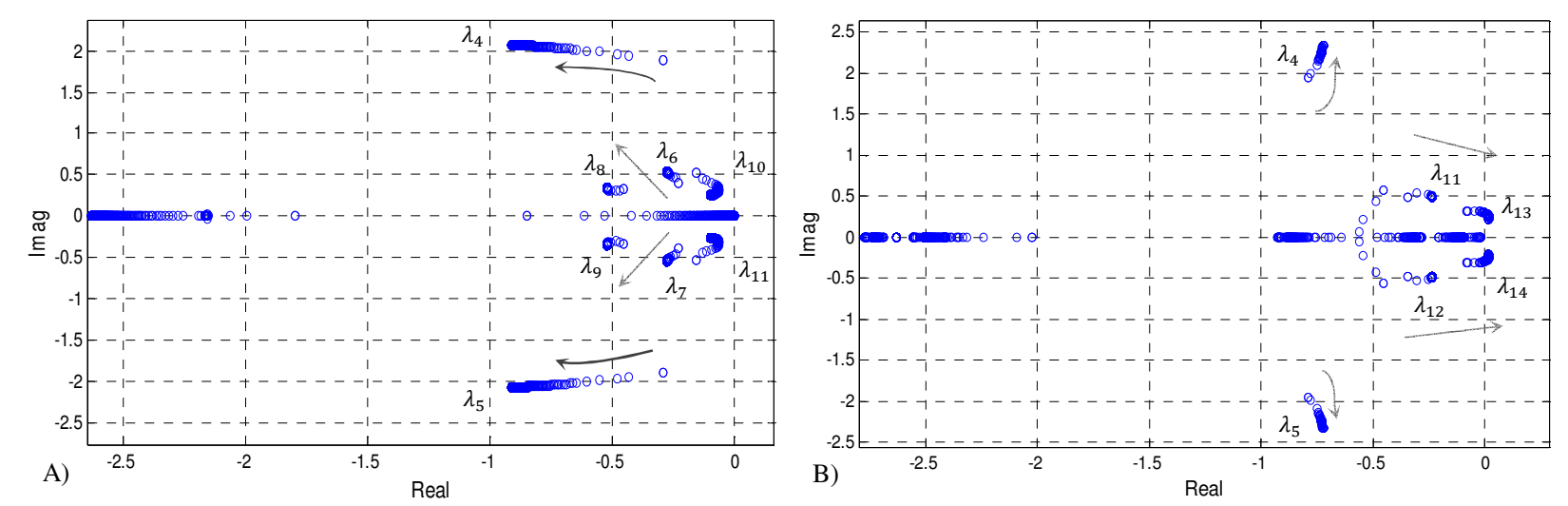

Fig. 13. Eigenvalue trajectory of dominant poles over $J_{\mathrm{i}}$ changes considering PLL model (arrow direction indicates increase in $J_{1}$ ).

In order to evaluate the system behaviours over a wide range of parameter variation with considering the PLL model, eigen trajectory is repeated considering the complete model of Eq. (27). In Fig. 13, the movements of all modes after changing the derivative control gains for a very wide range is presented. The general trend is the same as the one presented in Fig.8, but it is obvious that after adding PLL more couples of oscillatory modes are appearing. The participations of different states are presented in Table VI.

TABLE VI

PARTICIPATION OF SYSTEM STATES FOR DiFFERENT MODES.

\begin{tabular}{|c|c|c|}
\hline Modes & Associated states & Participation factors \\
\hline$\lambda_{1}$ & $\Delta P_{E S S 1}$ & 1.0041 \\
\hline$\lambda_{2}$ & $\Delta P_{E S S 2}$ & 1.0055 \\
\hline$\lambda_{3}$ & $\begin{array}{c}\Delta P_{t i e, D C}, \Delta \omega_{1}, \Delta \omega_{2} \\
\Delta X_{2, P 1}\end{array}$ & $\begin{array}{c}1.041,0.0051,0.003 \\
0.075\end{array}$ \\
\hline$\lambda_{4}$ & $\begin{array}{c}\Delta P_{t i e, A C}, \Delta \omega_{1}, \Delta \omega_{2} \\
\Delta X_{1, P 1}, \Delta X_{1, P 1}\end{array}$ & $\begin{array}{c}0.521,0.366,0.22 \\
0.191,0.529 \\
\end{array}$ \\
\hline$\lambda_{5}$ & $\begin{array}{c}\Delta P_{t i e, A C}, \Delta \omega_{1}, \Delta \omega_{2} \\
\Delta X_{1, P 1}, \Delta X_{1, P 1}\end{array}$ & $\begin{array}{c}0.521,0.366,0.22 \\
0.191,0.529\end{array}$ \\
\hline$\lambda_{6}$ & $\begin{array}{c}\Delta A C E_{1}, \Delta A C E_{2}, \Delta \omega_{1}, \Delta \omega_{2} \\
\Delta X_{1, P 1}, \Delta X_{1, P 1}\end{array}$ & $\begin{array}{c}0.177,0.12,0.26,0.155, \\
0.292,0.122\end{array}$ \\
\hline$\lambda_{7}$ & $\begin{array}{c}\Delta A C E_{1}, \Delta A C E_{2}, \Delta \omega_{1}, \Delta \omega_{2} \\
\Delta X_{1, P 1}, \Delta X_{1, P 1}\end{array}$ & $\begin{array}{c}0.177,0.12,0.26,0.155, \\
0.292,0.122\end{array}$ \\
\hline$\lambda_{8}$ & $\begin{array}{c}\Delta A C E_{2}, \Delta X_{1, P 1}, \Delta X_{1, P 1} \\
\Delta X_{1, P 2}, \Delta X_{1, P 2}\end{array}$ & $\begin{array}{c}0.112,0.145,0.248 \\
0.446,0.395 \\
\end{array}$ \\
\hline$\lambda_{9}$ & $\begin{array}{c}\Delta A C E_{2}, \Delta X_{1, P 1}, \Delta X_{1, P 1}, \\
\Delta X_{1, P 2}, \Delta X_{1, P 2}\end{array}$ & $\begin{array}{c}0.112,0.145,0.248 \\
0.446,0.395\end{array}$ \\
\hline$\lambda_{10}$ & $\Delta A C E_{1}, \Delta X_{1, P 1}$ & $0.8875,0.0513$ \\
\hline$\lambda_{11}$ & $\triangle A C E_{1}, \Delta X_{1, P 1}$ & $0.8875,0.0513$ \\
\hline$\lambda_{12}$ & $\begin{array}{c}\Delta A C E_{2}, \Delta \omega_{2}, \Delta X_{1, P 1}, \Delta X_{1, P 1}, \\
\Delta X_{1, P 2}, \Delta X_{1, P 2}\end{array}$ & $\begin{array}{l}0.603,0.491,0.156 \\
0.278,0.173,0.375\end{array}$ \\
\hline$\lambda_{13}$ & $\Delta P_{m 3}, \Delta P_{m 4}, \Delta \omega_{2}$ & $0.4189,0.8504,0.2071$ \\
\hline$\lambda_{14}$ & $\Delta P_{m 1}, \Delta P_{m 2}, \Delta \omega_{1}$ & $0.5619,0.5362,0.0804$ \\
\hline$\lambda_{15}$ & $\Delta P_{m 1}, \Delta P_{m 2}$ & $0.4881,0.5119$ \\
\hline$\lambda_{16}$ & $\Delta P_{m 3}, \Delta P_{m 4}$ & $0.7171,0.2922$ \\
\hline
\end{tabular}

Based on the obtained result, it can be observed that which states have more participation in sensitive modes. For example two of the sensitive modes from the eigenvalue analysis is $\lambda_{1}$ and $\lambda_{2}$. After checking the participation factor matrix, it become clear that $\Delta P_{E S S 1}$ and $\Delta P_{E S S 1}$ have the most participation in those modes. Therefore, controlling these state $\left(\triangle P_{E S S 1}\right.$ and $\left.\Delta P_{E S S 1}\right)$ are the most important ones for control design.
Another comparison regarding eigenvalue of the systems with and without PLL effects are presented by Table VII. It is clear that by adding PLL dynamics, the number of oscillatory modes will increase from 4 to 8 modes which deteriorate the dynamic performance of the system by increasing the oscillations and settling time of the system. Some oscillatory modes are also close to zero.

TABLE VII

EIGENVALUE COMPARISONS FOR DIFFERENT TWO-AREA SYSTEMS.

\begin{tabular}{|c|c|c|}
\hline Modes & $\begin{array}{c}\text { AC/DC with } \\
\text { Derivative Control }\end{array}$ & $\begin{array}{c}\text { AC/DC with Derivative } \\
\text { Control and PLL }\end{array}$ \\
\hline$\lambda_{\mathbf{1}}$ & -209.32 & -134.07 \\
\hline$\lambda_{\mathbf{2}}$ & -52.96 & -39.375 \\
\hline$\lambda_{\mathbf{3}}$ & -22.63 & -23.740 \\
\hline$\lambda_{\mathbf{4}}$ & $-1.1+1.9 \mathrm{i}$ & $-0.791+1.961 \mathrm{i}$ \\
\hline$\lambda_{\mathbf{5}}$ & $-1.1-1.9 \mathrm{i}$ & $-0.791-1.961 \mathrm{i}$ \\
\hline $\boldsymbol{\lambda}_{\mathbf{6}}$ & -0.201 & $-0.450+0.520 \mathrm{i}$ \\
\hline$\lambda_{\mathbf{7}}$ & $-0.1+0.2 \mathrm{i}$ & $-0.450-0.520 \mathrm{i}$ \\
\hline$\lambda_{\mathbf{8}}$ & $-0.1-0.2 \mathrm{i}$ & $-0.341+0.501 \mathrm{i}$ \\
\hline$\lambda_{\mathbf{9}}$ & -2.30 & $-0.341-0.501 \mathrm{i}$ \\
\hline $\boldsymbol{\lambda}_{\mathbf{1 0}}$ & -2.50 & $-0.078+0.503 \mathrm{i}$ \\
\hline$\lambda_{\mathbf{1 1}}$ & -2.70 & $-0.078-0.503 \mathrm{i}$ \\
\hline$\lambda_{\mathbf{1 2}}$ & -2.63 & -0.2102 \\
\hline$\lambda_{\mathbf{1 3}}$ & ------ & -2.041 \\
\hline$\lambda_{\mathbf{1 4}}$ & ----- & -2.423 \\
\hline$\lambda_{\mathbf{1 5}}$ & ----- & -2.631 \\
\hline$\lambda_{\mathbf{1 6}}$ & ----- & -2.690 \\
\hline
\end{tabular}

In order to analyse the dynamic effects of PLL for various parameters, more numerical analyses are presented in Fig. 14. In this comparisons, both PLLs are using the same values for their parameters $\left(\zeta_{1}=\zeta_{2}=\zeta\right.$ and $\left.\omega_{1}=\omega_{2}=\omega_{n}\right)$.

The frequency deviation in area one is presented in Fig. 14. It is assumed that the value for $\zeta$ is equal to 1.2 and the other parameter, $\omega_{n}$, is changing for comparing different dynamics effects of PLL measurements over the system behaviour.

Based on the presented results, it is obvious that the effects of PLL could be explained based on its time response. When the time constant is too high, it could be observe that the real effects of derivative control will be cancelled out. In this situation more oscillation will appear and the dynamic behaviour could be deteriorated. 
As shown in Fig. 14, when the values of $\omega_{n}$ are very low (high time constant), the response of the system is oscillatory and is not acceptable. Additionally, it is obvious that for the higher values of $\omega_{n}$, the system start to show the effects of derivative term and especially the effects of PLL. Therefore, the derivative control is more effective but with more settling time.
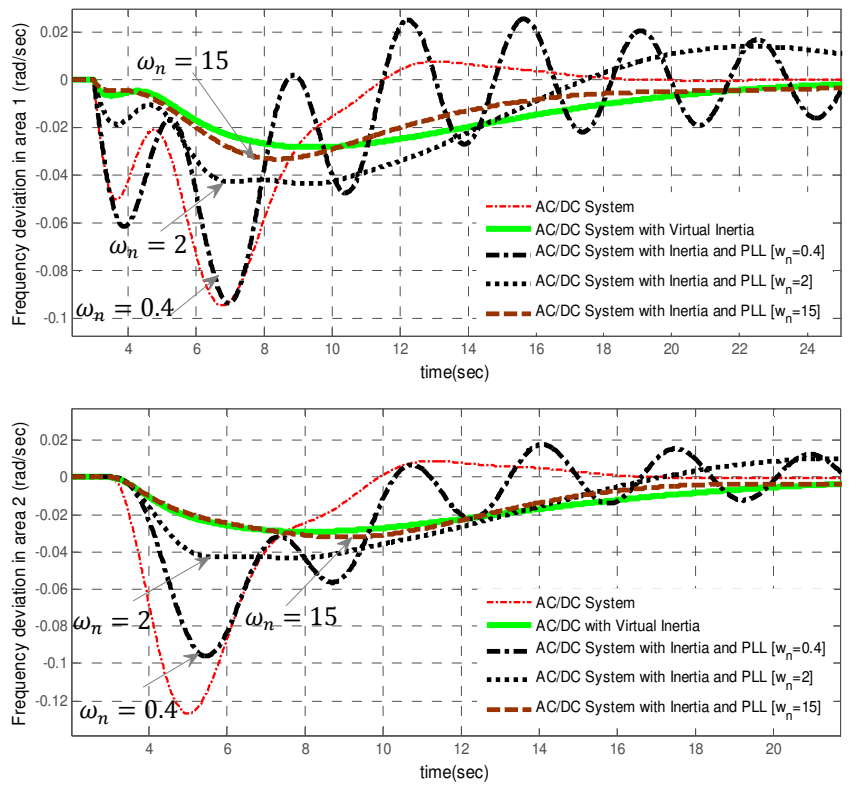

Fig. 14. Response of frequency deviations in both areas ( $\mathrm{rad} / \mathrm{sec})$.

\section{Performance Validation with Detailed Model}

This section presents detailed simulation results of the proposed control system. Simulation studies are carried out in the MATLAB/SIMULINK with all the details like PSS and AVR components under high-level AGC operation in the system. The dynamic parameters of the AC system is also given in Table VIII. Each area consists of two generators, each having a rating of $900 \mathrm{MVA}$ and $20 \mathrm{kV}$. The transmission system nominal voltage is $230 \mathrm{kV}$. The loads are located at buses 7 and 9, demanding total active power of $2734 \mathrm{MW}$ (967 MW in Area1 and 1767 MW in Area2.) The rest of the data can be found in [1].

TABLE VIII

PARAMETERS OF INTERCONNECTED SYSTEM

\begin{tabular}{|c|c|c|c|c|c|}
\hline Name & Bus & Rated power & V & H (s) & R \\
\hline GENCO1 & 1 & $900 \mathrm{MW}$ & $20 \mathrm{kV}$ & 6.5 & 0.05 \\
\hline GENCO2 & 2 & $900 \mathrm{MW}$ & $20 \mathrm{kV}$ & 6.5 & 0.06 \\
\hline GENCO3 & 3 & $900 \mathrm{MW}$ & $20 \mathrm{kV}$ & 6.175 & 0.05 \\
\hline GENCO4 & 4 & $900 \mathrm{MW}$ & $20 \mathrm{kV}$ & 6.175 & 0.06 \\
\hline
\end{tabular}

In this model the HVDC link is located in parallel with AC line. As shown in Table IX, this parallel transmission corridor consists of $345 \mathrm{kV}$ of AC line and two terminal VSC-HVDC links with $600 \mathrm{kV}$ of pole to pole rated DC link voltage.

TABLE IX

PARAMETERS OF HVDC SYSTEM

\begin{tabular}{|l|c|}
\hline Rated Power MVA & $500 \mathrm{MVA}$ \\
\hline Rated DC side voltage & $600 \mathrm{kV}$ \\
\hline Rated AC side voltage & $345 \mathrm{kV}$ \\
\hline DC link capacitor & $600 \mu \mathrm{F}$ \\
\hline Frequency & $60 \mathrm{~Hz}$ \\
\hline
\end{tabular}

In this study, it is also assumed that $600 \mathrm{MW}$ of power is transferring from Area1 to Area2, while after adding the HVDC link $200 \mathrm{MW}$ of this power will be transferred using HVDC system. The ratings of HVDC converters are assumed to be $500 \mathrm{MW}$ and the rating of ESS converter are $200 \mathrm{MW}$. It is assumed that at $t=170 \mathrm{~s}$ a huge decrement around $250 \mathrm{MW}$ happened in Area2 with the load of DISCO2. This load variation will affect the dynamic of the system and the response of virtual inertia is validated as shown in Figs. 15-20.

The voltage terminal of all generators are presented in Fig. 15, showing an acceptable performance of AVR especially after load reduction in Area2.
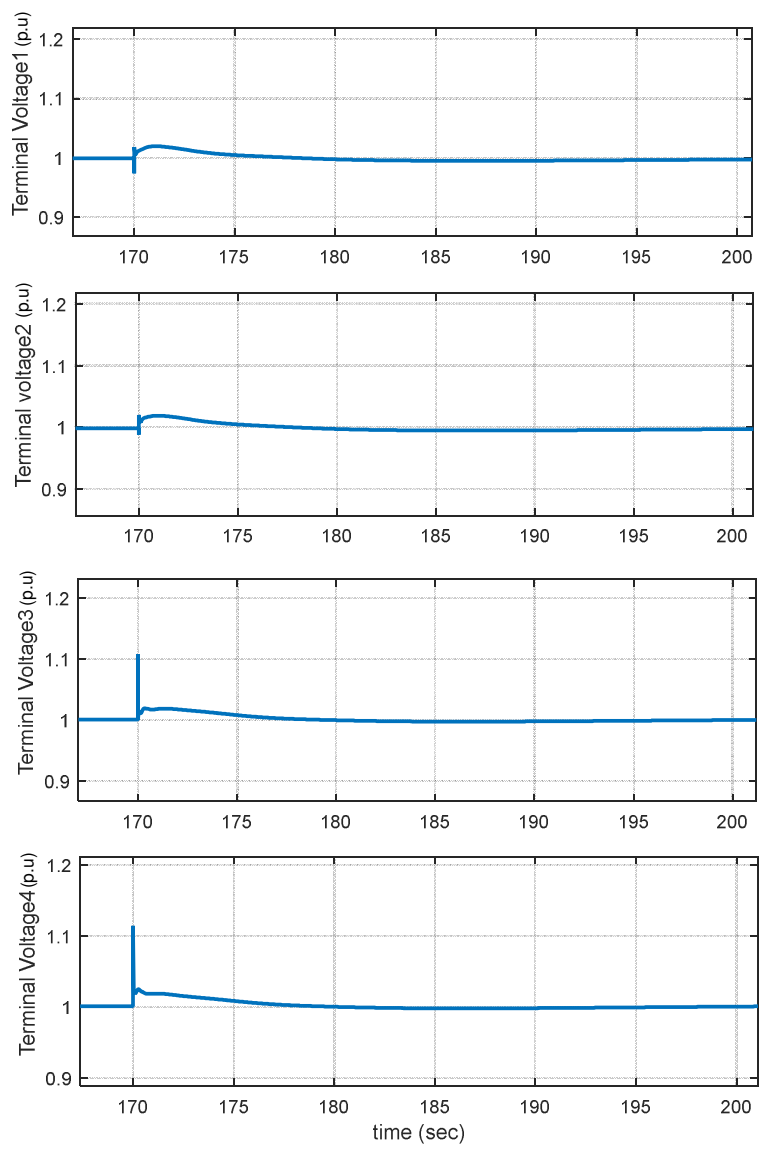

Fig. 15. Terminal voltage of generators (p.u).

The dynamic response of DC power is also presented in Fig. 16. It shows the fast response of HVDC converter on controlling the power around $200 \mathrm{MW}$ (Power reference is 0.4 pu. for $500 \mathrm{MW}$ rated power).

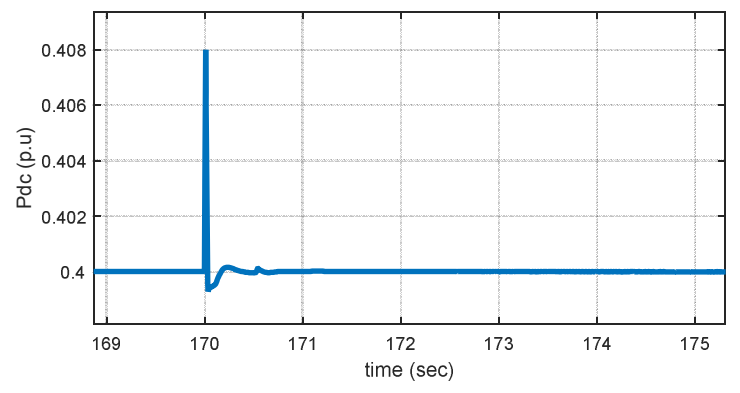

Fig. 16. Terminal voltage of generators (rating of $500 \mathrm{MW}$ ). 


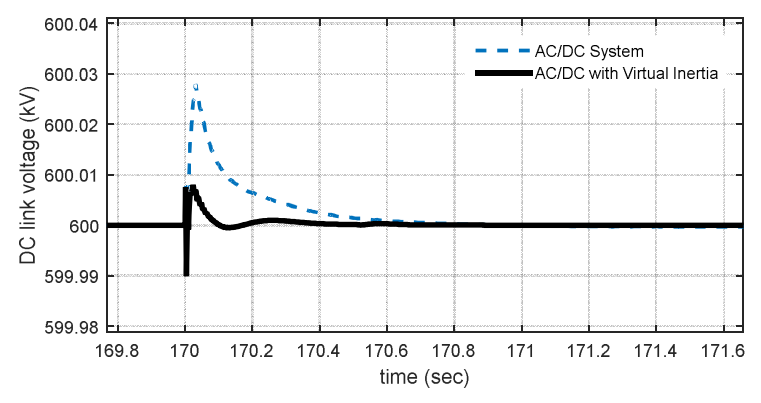

Fig. 17. Terminal voltage of generators (p.u).

The DC link voltage of HVDC link is also presented in Fig. 17, comparing the AC/DC systems with and without virtual inertia on maintaining the power balance through the DC link. It is obvious that after adding virtual inertia, oscillations on DC link is reduced. Emulated power from different ESS with virtual inertia controllers are presented in Fig. 18. The main contribution is from second controller located in Area2.

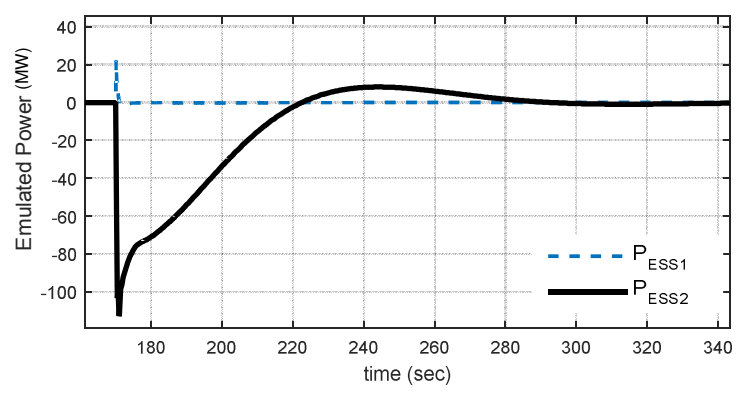

Fig. 18. Emulated power by ESS components (MW).

The frequency deviations are presented in Fig. 19. Based on the presented results, remarkable improvement is achieved in damping of frequency oscillation. The blue line is related to the AC/DC system which shows that DC link will contribute only on damping of oscillation by improving the settling time of the system without especial improvements in first overshoot. But after implementing the virtual inertia into the DC links, more improvements is appeared in reducing the first overshoot of frequency.
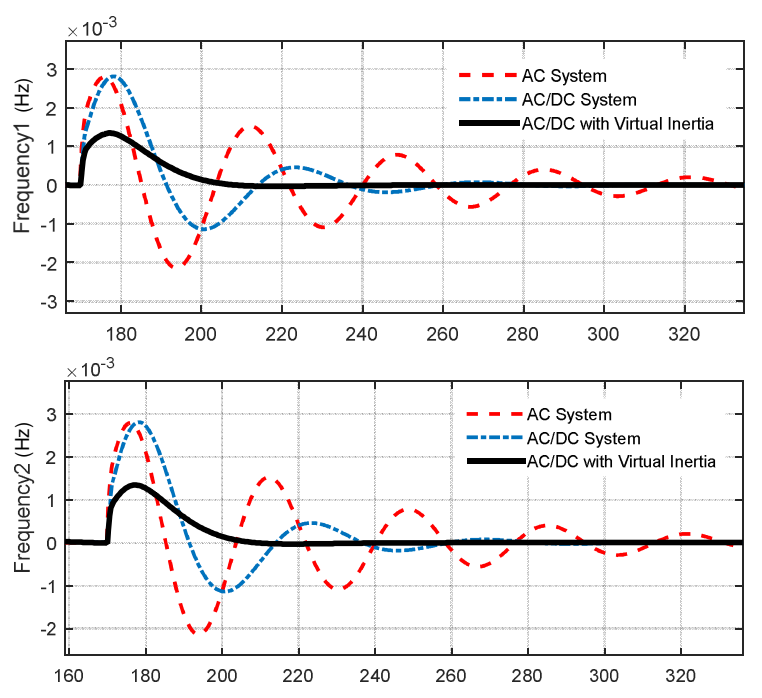

Fig. 19. Dynamic response of frequency in both areas $(\mathrm{Hz})$.
The output power of all generators are presented in Fig. 20. Based on the AGC concept, the main demanded loads should be responded by the responsible generators at the same area, which is clear in Fig 20, while GENCOs 3 and 4 is reducing its output after load reduction in DISCO2.
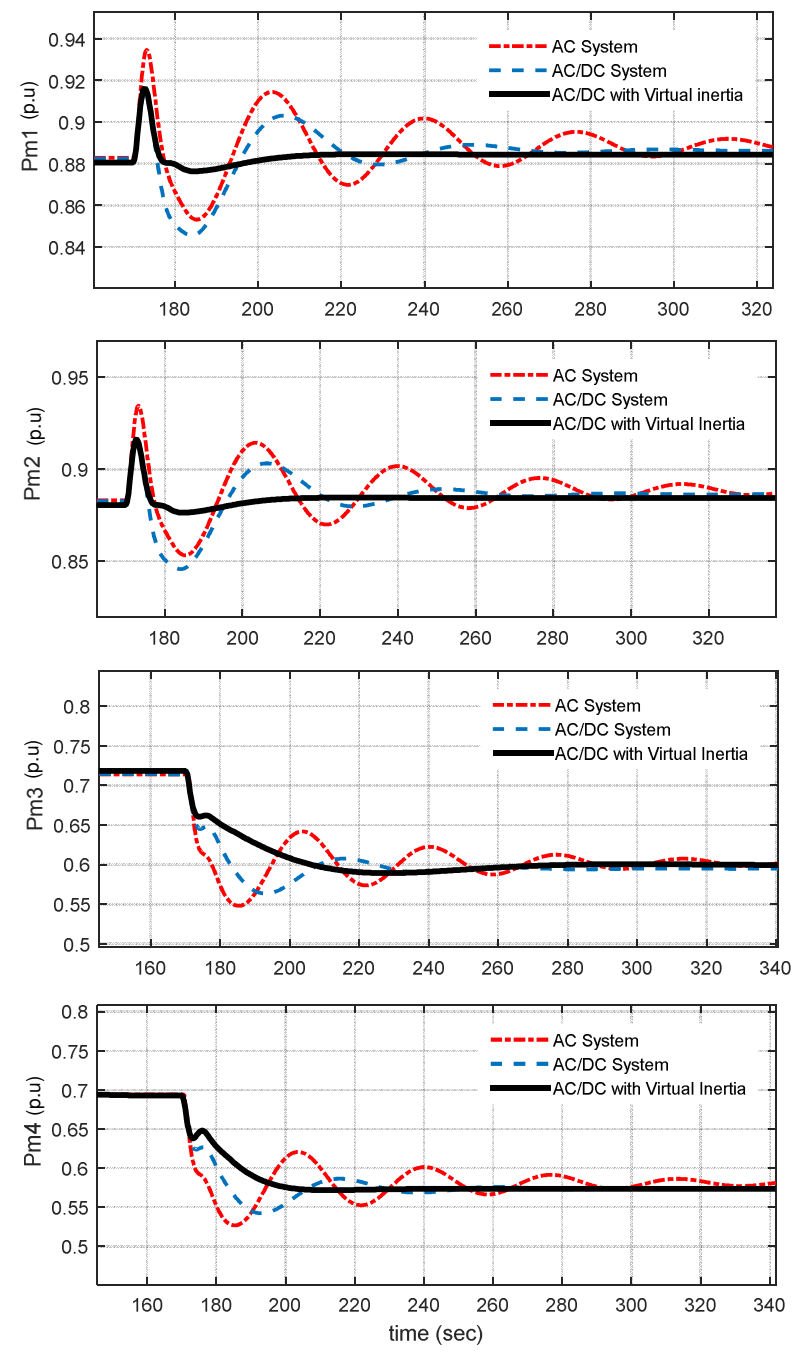

Fig. 20. Output of GENCOS (pu.).

Considering the results in Figs. 18 and 20, it is worth mention that, the maximum value of absorbed power from ESS2 is happening in a very short time after load variation. Response of electronic ESS compare to mechanical power of conventional generators. Obtained results through this analysis can identify the ratings of necessity facilities for converter stations in different applications.

\section{CONCLUSION}

In this paper, a new approach for implementing the virtual inertia in two-area AC/DC interconnected system is proposed. The proposed formulation could be easily implemented for any type of interconnected power systems with different size and characteristics. Derivative control technique is used for control the stored energy of converter devices in AC/DC interconnected AGC power system. The effects of frequency measurement and PLL are also considered in this paper. Based on presented information, inertia emulation using derivative 
control in AC/DC interconnection could help the system during sever contingencies. It is shown through the different analysis and simulations that proposed approach is improving significantly the stability of the system.

\section{REFERENCES}

[1] P. Kundur, Power System Stability and Control, New York: McGrawHill, 1994.

[2] V. Donde, A. Pai, and I. A. Hiskens, "Simulation and optimization in a AGC system after deregulation," IEEE Trans. Power Syst., vol. 16, no. 3, pp. 481-489, August 2001.

[3] E. Rakhshani, and P. Rodriguez, "Active Power and Frequency Control Considering Large Scale RES," in Large Scale Renewable Power Generation, Springer-Verlag: Berlin Heidelberg, 2014, pp. 233-271.

[4] G. Delille, B. Francois, G. Malarange,,"Dynamic Frequency Control Support by Energy Storage to Reduce the Impact of Wind and Solar Generation on Isolated Power System's Inertia," IEEE Transactions on Sustainable Energy, Vol. 3, Issue 4, pp. 931-939, 2012.

[5] H. Bevrani, and S. Shokoohi, "An Intelligent Droop Control for Simultaneous Voltage and Frequency Regulation in Islanded Microgrids," IEEE Transactions on Smart Grid, Vol. 4, No. 4, 2013.

[6] M. Datta, and T. Senjyu, "Fuzzy Control of Distributed PV Inverters/Energy Storage Systems/Electric Vehicles for Frequency Regulation in a Large Power System," IEEE Transactions on Smart Grids, vol. 4, No. 1, March 2013.

[7] Y.P. Agalgaonkar, B.C. Pal and R.A. Jabr, "Distribution Voltage Control Considering the Impact of PV Generation on Tap Changers and Autonomous Regulators," IEEE Transactions on Power Systems, vol.29, no.1, pp.182-192, January 2014.

[8] M. Datta, H. Ishikawa, H. Naitoh, T. Senjyu, "LFC by coordinated virtual inertia mimicking and PEVs in power utility with MW-class distributed PV generation," IEEE 13th Workshop on Control and Modeling for Power Electronics, pp. 1-8, 2012.

[9] J. Driesen, K. Visscher, "Virtual synchronous generators," IEEE Proc. on Power and Energy Society-General Meeting, pp. 1-3, 2008.

[10] P. Rodriguez, J. Ignacio Candela and A. Luna, "Control of PV Generation Systems using a Synchronous Power Controller," IEEE Energy Conversion Congress and Exposition, ECCE, USA, 2013.

[11] Z. Miao, L. Fan, D. Osborn, and S. Yuvarajan, "Wind Farms With HVdc Delivery in Inertial Response and Primary Frequency Control," IEEE Transactions on Power Systems, Vol. 25, No. 4, 2010.

[12] E. Rakhshani, A. Luna, K. Rouzbehi, P. Rodriguez, and I. EtxeberiaOtadui, "Effects of VSC-HVDC on Load Frequency Control in MultiArea Power System," IEEE Energy Conversion Congress and Exposition, ECCE, pp. 4432-4436, 2012.

[13] S. Nomura, H. Tsutsui, S. Tsuji-Iio, R. Shimada, "Flexible Power Interconnection With SMES," IEEE Transactions on Applied Superconductivity, vol. 16, no. 2, pp. 616-619, 2006.

[14] Z. Jiebei, C.D. Booth, G.P. Adam, A.J. Roscoe, C.G. Bright, "Inertia Emulation Control Strategy for VSC-HVDC Transmission Systems," IEEE Transactions on Power Systems, Vol. 28, Issue 2, 2013.

[15] R.A. Jabr, I. Dzafic, B.C. Pal, "Robust Optimization of Storage Investment on Transmission Networks," IEEE Transactions on Power Systems, Vol. 30, Issue 1, pp. 531-539, 2015.

[16] M.J. Carrizosa, F.D. Navas, G. Dammc, F.L. Lagarrigue, "Optimal power flow in multi-terminal HVDC grids with offshore wind farms and storage devices," Electrical Power and Energy Systems, 2015.

[17] A. Castillo, D.F. Gayme, "Grid-scale energy storage applications in renewable energy integration: A survey," Energy Conversion and Management, vol. 87, pp. 885-894, 2014.

[18] S.K. Aditya, D. Das, "Battery energy storage for load frequency control of an interconnected power system", Electric Power Systems Research, vo. 58 , pp. 179-185, 2001.

[19] M. Mufti, S.A., S.J. Iqbal, M. Ahmad, M. Ismail, "Super-capacitor based energy storage system for improved load frequency control", Electric Power Systems Research, vol. 79, pp. 226-233, 2009.

[20] K.R. Sudha, R. Vijaya Santhi, "Load Frequency Control of an Interconnected Reheat Thermal system using Type-2 fuzzy system including SMES units", Electrical Power and Energy Systems, 2012.

[21] E. Rakhshani, J. Sadeh, "Practical Viewpoints on Load Frequency Control Problem in a Deregulated Power System", Energy conversion and management, Vol. 51. Issue 6. pp. 1148-1156. June 2010.
[22] Z. Du, Y. Zhang, Z. Chen, P. Li, Y. Ni, L. Shi, "Integrated emergency frequency control method for interconnected AC/DC power systems using centre of inertia signals", IET Generation, Transmission \& Distribution, vol. 6, pp. 584-592, 2012.

[23] R. Teodorescu, M. Liserre, P. Rodriguez, Grid Converters for Photovoltaic and Wind Power Systems. New York: IEEE-Wiley, 2011.

[24] M. Benidris, J. Mitra, "Enhancing Stability Performance of Renewable Energy Generators by Utilizing Virtual Inertia", IEEE Power and Energy Society General Meeting, 2012.

\section{BIOGRAPHIES}

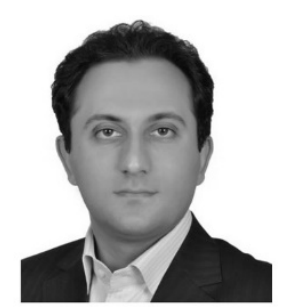

Elyas Rakhshani received his $\mathrm{PhD}$ degree in Electrical Engineering from Technical University of Catalonia (UPC), SEER research center, Spain in 2016. Previous to that, he also obtained his M.Sc. degree in Control Systems in 2008 and B.Sc. degree in Power Systems in 2000 from Iran.

From 2013 he also joined Abengoa Company, ABENGOA Research department (in Seville, Spain) as a researcher, working on different projects related to modern power systems.

His research interests are power system control, dynamics and stability; HVDC control and power converter applications in power systems; frequency control and optimal intelligent control.

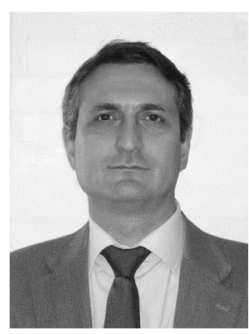

Pedro Rodriguez (SM'10-F'13) received the M.Sc. and $\mathrm{Ph} . \mathrm{D}$. degrees in electrical engineering from the Technical University of Catalonia (UPC), Barcelona, Spain, in 1994 and 2004, respectively. He was a PostDoctoral Researcher at the Center for Power Electronics Systems, Virginia Tech, USA, in 2005, and at the Department of Energy Technology, Aalborg University (AAU), Denmark, in 2006. He joined the faculty of UPC as an Assistant Professor in 1990, where he became the Director of the Research Center on Renewable Electrical Energy Systems, Department of Electrical Engineering. He is currently a part time Professor with UPC. He was also a Visiting Professor at AAU from 2007 to 2011, and a Co-Supervisor of the Vestas Power Program. In 2011, he joined Abengoa, Seville, Spain, as the Director of Technology on Power Systems and Power Electronics. He has coauthored one book, over 70 papers in ISI technical journals and around 250 papers in conference proceedings. He is the holder of twelve licensed patents. He received the Best Technical Letter Award 2012 and the Second Best Paper Award 2012 in the IEEE Transactions on Power Electronics and the Second Paper Award 2014 in the IEEE Journal of Emerging and Selected Topics in Power Electronics. His current research interests include distributed power systems, flexible transmission systems, and power conversion.

Dr. Rodriguez is an IEEE Fellow for his contributions in the control of distributed generation, an Associate Editor of the IEEE TRANSACTION ON POWER ELECTRONICS. He was the Vice Chair of the Sustainability and Renewable Energy Committee of the IEEE Industry Application Society. 